\title{
MICROSTRUCTURAL STUDY OF AZ91C MAGNESIUM ALLOY CASTINGS PRODUCED BY INVESTMENT CASTING IN AS-CAST STATE AND AFTER HEAT TREATMENT
}

\author{
Martin DYČKA, Lucie DYČKOVÁ, Pavel GEJDOŠ, \\ Martin JULIŠ

\begin{abstract}
Brno University of Technology, Central European Institute of Technology, Brno, Czech Republic, EU martin.dycka@ceitec.vutbr.cz, lucie.dyckova@ceitec.vutbr.cz, pavel.gejdos@ceitec.vutbr.cz, martin.julis@ceitec.vutbr.cz
\end{abstract}

https://doi.org/10.37904/metal.2019.928

\begin{abstract}
In this article, the microstructure of AZ91C magnesium alloy castings produced by investment casting was investigated. Castings were studied in as-cast state and after T4 and T6 heat treatment. The identification of all phases in microstructure was carried out using a scanning electron microscope (SEM) with energy dispersive X-ray spectroscopy (EDS) analysis. The influence of cooling rate after casting, temperature of solution annealing, temperature of artificial aging and cooling rate after heat treatment on the microstructural characteristics such as secondary dendrite arm spacing (SDAS) or grain size was studied. The SDAS analyses were carried out using a light microscopy with the subsequent image analysis. Except of Mg-Al solid solution and $\mathrm{Mg}_{17} \mathrm{Al}_{12}$ precipitates, the microstructure contains other phases based on $\mathrm{Mg}$-Si and ( $\left.\mathrm{Al}, \mathrm{Si}\right)-\mathrm{Mn}$ in globular or needle morphology. The SDAS in as-cast state was measured and was of tens of micrometers, but after T4 heat treatment, the gran size exceeded $100 \mu \mathrm{m}$ and the $\mathrm{Mg}_{17} \mathrm{Al}_{12}$ phase was still undissolved along the grain boundaries in samples with thicker wall dimension. After T6 heat treatment, continuous and discontinuous precipitates of $\mathrm{Mg}_{17} \mathrm{Al}_{12}$ phase were formed, most of them were nearby the grain boundaries proving the inhomogeneous distribution of $\mathrm{Al}$ atoms in solid solution after T4 heat treatment.
\end{abstract}

Keywords: Magnesium alloy, AZ91, investment casting, microstructure, heat treatment

\section{INTRODUCTION}

Many industrial areas in Europe face the problem of continuous climate change, which resulted in strong pressure on emission reduction of greenhouse gasses in all means of transportation. Especially automotive and aerospace industries are pushed very strongly to reduce emissions by the EU regulation 2016/1628. One way to reduce emissions in transport industry is to lower the weight of transport devices, this goal can be accomplished by replacing of heavy ferrous parts by lighter alloys, such as plastics, composites, aluminium alloys or magnesium alloys. Magnesium alloys of AZ, WE, ZK, ZW and other groups are already used by many manufacturers in automotive industry, the predominant processing technique is die casting [1].

Altrouht that die casted magnesium parts offer good combination of low weight, good mechanical properties and good surface quality, this technology can be economically used only for mass production of huge series. For small series production of magnesium alloy castings, conventional technologies face the problem of magnesium high reactivity with oxygen, resulting in bad surface quality and high number of casting defects. Promissing casting technology in this field is investment casting, which is suitable for production of complex shapes and thin walls [2,3]. It is well known that mechanical properties of castings strongly depend on microstructure: grain size and casting defects. Initial microstructure of casting in as-cast state then influences the process and result of subsequent heat treatment [4]. In this article, microstructure of AZ91C magnesium castings is studied both in as-cast state and after T4 and T6 heat treatment to find out the relationship between initial microstructure in as-cast state and microstructure after heat treatment. 


\section{EXPERIMENTAL SETUP}

Magnesium AZ91C alloy castings were produced using investment casting. Ceramic shells in this work were manufactured using conventional procedure, which includes the use of colloidal silica as a binder and mullite/molochite as ceramic slurry and stucco. Protective gas was used during pouring of liquid metal. To change the cooling rate of castings, ceramic shells were cooled down using different cooling intensity. One set of samples was examined in as cast state to get information about SDAS. Another set of samples was heat treated according to CSN EN 1753 standard [5] using T4 and T6 heat treatment conditions as prescribed in this standard. Casting and heat treatment conditions of all samples studied in this article are summarized in Table 1. Samples with different wall thickness were chosen to study the influence of wall thickness on SDAS together with influence of different cooling speed. Low cooling speed represents cooling of the shell out of the furnace at ambient temperature. Moderate and high cooling speeds were simulated using the flow of compressed air around the shell using different air pressure. Thermal gradient inside the shell was not measured. After T4 heat treatment, samples were cooled down in the water batch as prescribed in CSN standard. Cooling after T6 treatment was at the ambient temperature outside the furnace.

Table 1 Overview of samples studied in this work and their parameters

\begin{tabular}{|c|c|c|c|c|c|c|c|c|}
\hline \multirow{2}{*}{ Sample } & \multirow{2}{*}{$\begin{array}{c}\text { Wall } \\
\text { thickness } \\
(\mathrm{mm})\end{array}$} & $\begin{array}{c}\text { Cooling } \\
\text { speed } \\
(-)\end{array}$ & $\begin{array}{c}\text { Tempe- } \\
\text { rature } \\
\left({ }^{\circ} \mathrm{C}\right)\end{array}$ & $\begin{array}{c}\text { Holding } \\
\text { time } \\
(\mathrm{h})\end{array}$ & $\begin{array}{c}\text { Cooling } \\
\text { speed } \\
(-)\end{array}$ & $\begin{array}{c}\text { Tempe- } \\
\text { rature } \\
\left({ }^{\circ} \mathrm{C}\right)\end{array}$ & $\begin{array}{c}\text { Holding } \\
\text { time } \\
(\mathrm{h})\end{array}$ & $\begin{array}{c}\text { Cooling } \\
\text { speed } \\
(-)\end{array}$ \\
\hline A1 a & 6 & low & - & - & - & - & - & - \\
\hline A1 b & 10 & low & - & - & - & - & - & - \\
\hline A2 a & 6 & moderate & - & - & - & - & - & - \\
\hline A2 b & 10 & moderate & - & - & - & - & - & - \\
\hline A3 a & 3 & fast & - & - & - & - & - & - \\
\hline A3 b & 6 & fast & - & - & - & - & - & - \\
\hline A3 c & 9 & fast & - & - & - & - & - & - \\
\hline B1 & 2 & low & 415 & 20 & fast & - & - & - \\
\hline B2 & 18 & low & 415 & 20 & fast & - & - & - \\
\hline C1 & 10 & low & 415 & 20 & fast & 170 & 16 & slow \\
\hline C2 & 10 & moderate & 415 & 20 & fast & 170 & 16 & slow \\
\hline
\end{tabular}

Casted and heat treated samples were cut and molded into resin to prepare metallographic samples. During preparation, standard grinding and polishing techniques were used using diamond suspensions with diamond size ranging from $9 \mu \mathrm{m}$ to $0.25 \mu \mathrm{m}$. As the final step, samples were etched using acetic-picric etchant for $A$ and $\mathrm{C}$ group samples or $2 \%$ Nital etchant for $\mathrm{B}$ group samples.

Light microscopy (DSX510, OLYMPUS) and electron microscopy (LYRA3, TESCAN) were used to study the microstructure of all samples. EDS analysis was used for chemical analysis and phase identification.

\section{EXPERIMENTAL RESULTS}

\subsection{Microstructure in as-cast state}

Microstructure of AZ91C magnesium alloy in as-cast state has a dendritic structure. Dependence of SDAS on cooling rate and wall thickness was studied on 3 sets of samples (A1, A2, A3), which were manufactured using different cooling rates. In each set of samples, there are at least 2 samples with different wall thickness 
as can be seen in Table 1. SDAS varies between $26 \mu \mathrm{m}$ and $35 \mu \mathrm{m}$ depending on cooling rate and wallthickness. Comparisons of influence of wall thickness and cooling rate on SDAS are shown in Figure 1 and Figure 2.

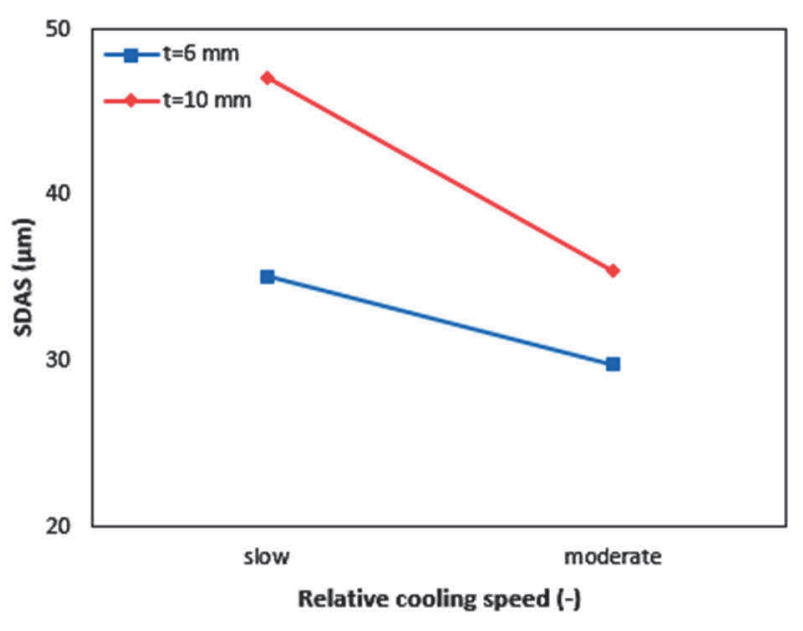

Figure 1 Dependence of SDAS on cooling rate

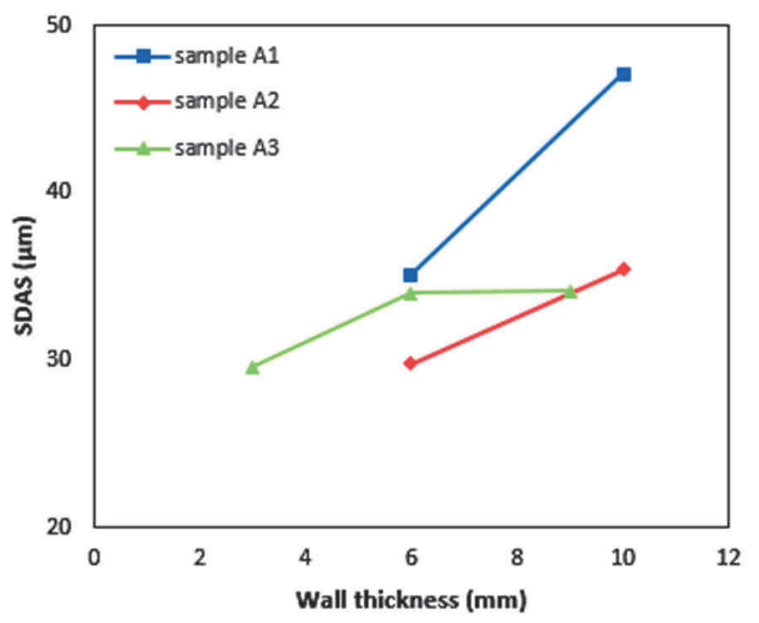

Figure 2 Dependence of SDAS on wall thickness

Microstructure of AZ91C magnesium alloy in as-cast state consists primarily of aMg solid solution forming dendrites and $\mathrm{Mg}_{17} \mathrm{Al}_{12}$ intermetallic phase filling remaining interdendritic regions. Except of these two phases, microstructure contains manganese-rich precipitates with needle-like and sharp-edged morphology. All these phases can be seen in Figure 3, the chemical composition of these phases is summarized in Table 2.

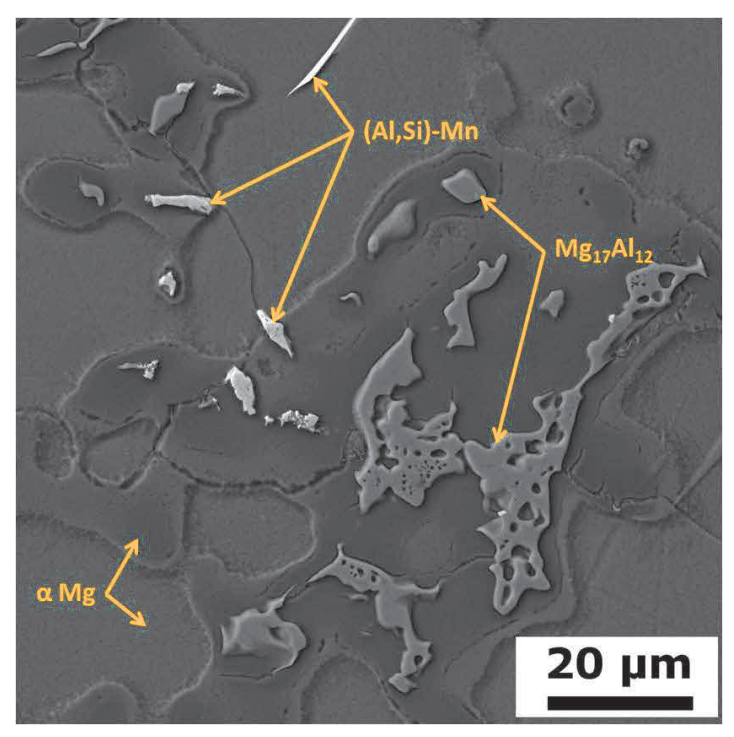

Figure 3 Microstructure of sample A1a

Table 2 Overview and chemical composition of analyzed phases in sample A1a

\begin{tabular}{|c|c|c|c|c|c|}
\hline Phase / Chemical composition & $\begin{array}{c}\text { Mg } \\
(\text { at\% })\end{array}$ & $\begin{array}{c}\text { Al } \\
(\text { at\%) }\end{array}$ & $\begin{array}{c}\text { Mn } \\
(\text { at\%) }\end{array}$ & $\begin{array}{c}\text { Si } \\
(\text { at\%) }\end{array}$ & $\begin{array}{c}\mathbf{Z n} \\
(\text { at\%) }\end{array}$ \\
\hline$\alpha$ Mg & rest & $2.8-15$ & - & - & $0-0.5$ \\
\hline Mg$_{17} \mathrm{Al}_{12}$ & rest & $32.9-34.5$ & - & - & $1.5-2.4$ \\
\hline$(\mathrm{Al}, \mathrm{Si})-M n$ precipitate (needle-like) & rest & $42.5-46.7$ & $24.3-27.7$ & $3.5-4.6$ & - \\
\hline$(\mathrm{Al}, \mathrm{Si})-M n$ precipitate (sharp-edge) & rest & $46.7-54.6$ & $16.7-20.8$ & $0.8-2.2$ & - \\
\hline
\end{tabular}




\subsection{Microstructure after heat treatment}

The first step in heat treatment process of AZ91C magnesium alloy is solution annealing, which was studied on two samples with different wall thickness (B1 and B2). Microstructure of sample with thinner wall of $3 \mathrm{~mm}$ contains no remaining $\mathrm{Mg}_{17} \mathrm{Al}_{12}$ phase (Figure 4), but the sample with thicker wall dimension contains remaining undissolved $\mathrm{Mg}_{17} \mathrm{Al}_{12}$ phase, proving that the hold time of 20 hours on T4 temperature was insufficient for complete dissolution of $\mathrm{Mg}_{17} \mathrm{Al}_{12}$ precipitates (Figure 5). The undesirable phenomenon connected with solution annealing is coarsening of microstructure. Grain size according to ISO 643 [9] was measured on both samples; the results are shown in Table 3. As can be seen, thinner sample exhibits smaller grain size, this is probably caused by significantly finer microstructure in as-cast state.

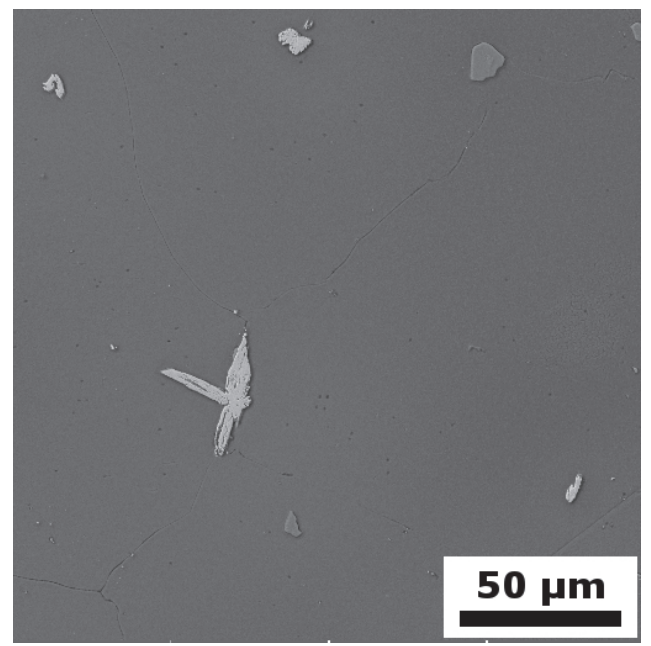

Figure 4 Microstructure of B1 sample

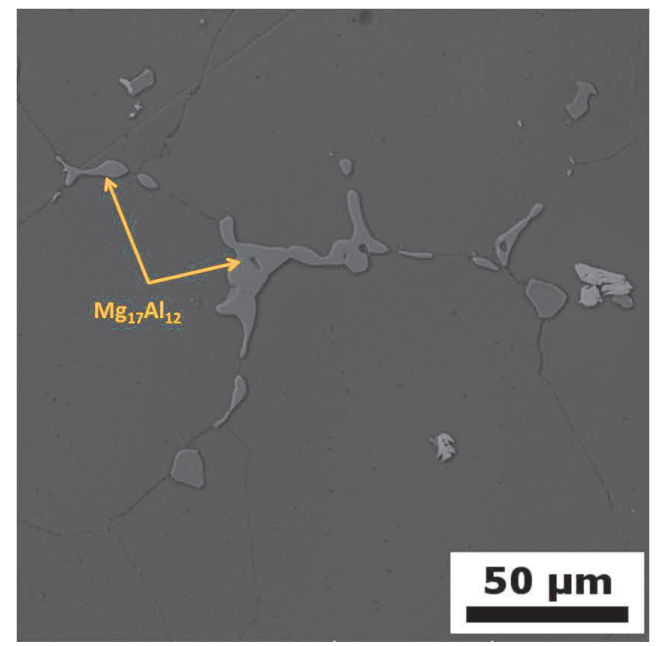

Figure 5 Microstructure of B2 sample showing undissolved $\mathrm{Mg}_{17} \mathrm{Al}_{12}$ precipitates

Table 3 Results of grain size measurement

\begin{tabular}{|c|c|c|}
\hline Sample & Grain size (-) & Wall thickness (mm) \\
\hline B1 & 2.8 & 2 \\
\hline B2 & 3.3 & 18 \\
\hline
\end{tabular}

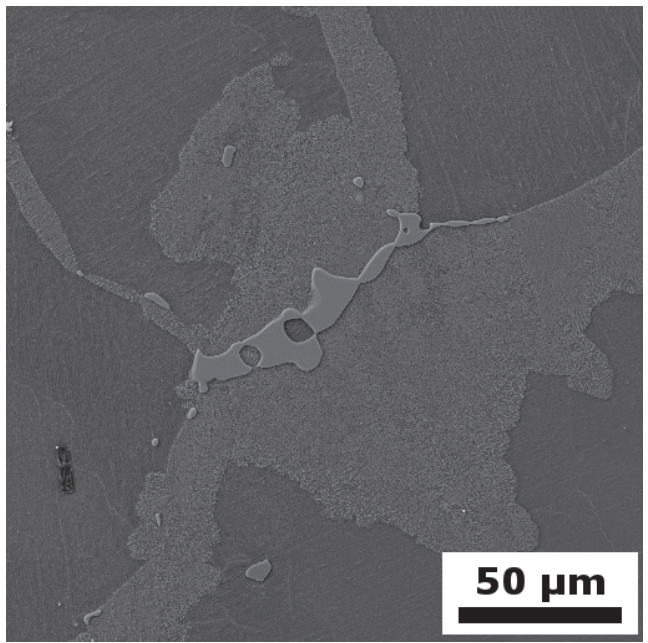

Figure 6 Microstructure of C2 sample

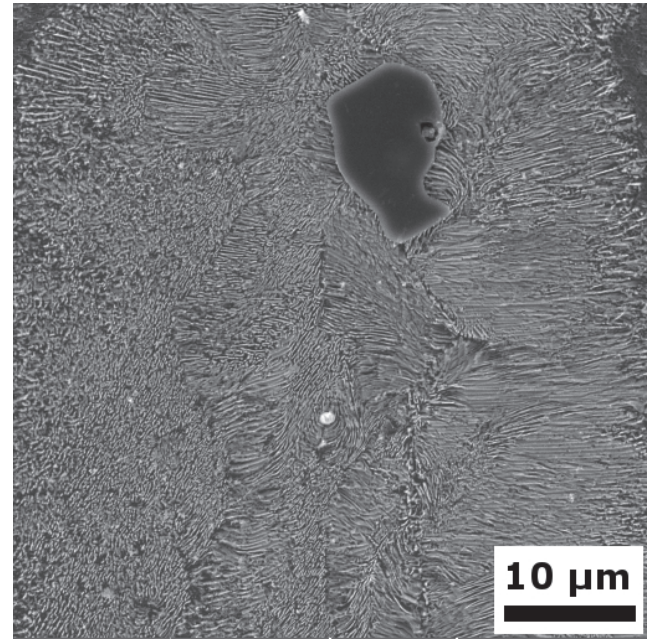

Figure 7 Microstructure of C2 sample, detail of discontinuous precipitates along the grain boundary 
The microstructure of AZ91C alloy after solution annealing consists mainly of Mg solid solution with inclusions that were characterized in section 3.1. (Figure 3, Table 2). After T6 heat treatment, large colonies of discontinuous $\mathrm{Mg}_{17} \mathrm{Al}_{12}$ precipitates formed, mostly along the grain boundaries (Figure 6 and Figure 7). Microstructure of $\mathrm{C} 2$ sample (Figure 6) contains remaining massive $\mathrm{Mg}_{17} \mathrm{Al}_{12}$ precipitates, which were not dissolved during solution annealing. Microstructure after T6 heat treatment still contains all inclusions that were observed in as-cast state or after T4 heat treatment

\section{DISCUSSION}

Microstructural characteristics like SDAS are strongly influenced both by cooling rate during casting process and wall thickness. According to the prediction, low cooling intensity resulted in the high SDAS value [2,4]. However there has been observed only slight difference in SDAS while moderate or high cooling intensities were used. This is probably caused by the low thermal conductivity of ceramic shell, which becomes the limiting factor in heat transfer from the metal to the cooling media. This implies that further increase of ceramic shell outer surface cooling intensity will not significantly improve SDAS of final casting.

There have been identified many phases in microstructure of AZ91C magnesium alloy, in addition to $\mathrm{aMg}$ solid solution and $\mathrm{Mg}_{17} \mathrm{Al}_{12}$ massive and discontinuous precipitates, ( $\left.\mathrm{Al}, \mathrm{Si}\right)-\mathrm{Mn}$ precipitates with needle-like and sharp-edged morphology were observed in microstructure. Mn-based phases were reported also by [2,6-7]. Needle like shape of (Al,Si)-Mn precipitates could have deteriorating effect on mechanical properties of final casting. However, silicon content up to 2.5 at\% in AZ91 alloys is considered as beneficial as it forms small sharp-edged Mg-Si precipitates in microstructure enhancing mechanical properties of the alloy [6-7].

\section{CONCLUSION}

The main goal of solution annealing, to dissolve continuous $\mathrm{Mg}_{17} \mathrm{Al}_{12}$ precipitates and to homogenize $\mathrm{Mg}$ solid solution, was only partially accomplished. Samples with bigger wall thickness still contain undissolved $\mathrm{Mg}_{17} \mathrm{Al}_{12}$ continuous precipitates, which can decrease the effect of following T6 heat treatment. The same result was reported by [8]. Homogeneity of Mg solid solution after T4 is also insufficient as can be observed after T6, where discontinuous precipitates were formed only along the grain boundaries, where aMg solid solution was enriched with aluminum.

\section{ACKNOWLEDGEMENTS}

This research was financially supported by project from the Ministry of Industry and Trade No.: FV30305. We also acknowledge CEITEC Nano Research Infrastructure (MEYS CR, 2016-2019) for providing us with access to the SEM devices.

\section{REFERENCES}

[1] KAINER, Karl U. (ed.). Magnesium alloys and technologies. John Wiley \& Sons, 2006. 293 p.

[2] SIN, S. Lun, DUBÉ, D and TREMBLAY, R. An investigation on microstructural and mechanical properties of solid mould investment casting of AZ91D magnesium alloy. Materials characterization. 2008. vol. 59, no. 2, pp. 178187.

[3] Al, Xiulan and QUAN, Gaofeng. Effect of Ti on the mechanical properties and corrosion of cast AZ91 magnesium alloy. The Open Materials Science Journal. 2012. vol. 6, no. 1, pp. 6-13.

[4] DO LEE, Choong and SHIN, Kwang Seon. Effects of precipitate and dendrite arm spacing on tensile properties and fracture behavior of As-Cast magnesium-aluminum alloys. Metals and Materials International. 2003. vol. 9, no. 1, pp. 21-27.

[5] ČSN EN 1753 Magnesium and magnesium alloys - Magnesium alloy ingots and castings. Prague: Institute for technical normalization, metrology and testing. 1999. p. 16, 421484. 
[6] JAIN, V., et al. Study of $\beta$-precipitates and their effect on the directional yield asymmetry of friction stir processed and aged AZ91C alloy. Materials Science and Engineering: A. 2013. vol. 560, pp. 500-509.

[7] FENG, Xue, XUEGANG, Min and YANGSHAN, Sun. Microstructures and mechanical properties of AZ91 alloy with combined additions of $\mathrm{Ca}$ and Si. Journal of materials science. 2006. vol. 41, no. 15, pp. 4725-4731.

[8] LI, Jing-Yuan, et al. Microstructural evolution of AZ91 magnesium alloy during extrusion and heat treatment. Transactions of Nonferrous Metals Society of China. 2012. vol. 22, no. 5, pp. 1028-1034.

[9] ČSN EN ISO 643, Steels - Micrographic determination of the apparent grain size. Prague: Institute for technical normalization, metrology and testing. 1999. p. 36, 420462. 